\title{
Case Report: Extracorporeal Membrane Oxygenation In Curing A Young Man Post-Operative of The Modified Fontan Operation
}

Hebing Guo

Capital Medical University

Jianbo Tan

Capital Medical University

Yongchao Cui

Capital Medical University

Haofeng Xiong

Capital Medical University

Chuansheng Li

Capital Medical University

Yufeng Liu

Capital Medical University

Yao Sun

Capital Medical University

Lin $\mathrm{Pu}$

Capital Medical University

\section{Pan Xiang}

Capital Medical University

Ming Zhang

Capital Medical University

Jingjing Hao

Capital Medical University

Ningning Yin

Capital Medical University

\section{Xiaotong Hou}

Capital Medical University

Jingyuan Liu ( $\nabla$ dtyyicu@ccmu.edu.cn )

Capital Medical University https://orcid.org/0000-0002-0592-9789 
Keywords: acute respiratory distress syndrome, extracorporeal membrane oxygenation, modified Fontan operation, Influenza A, Tausing-Bing syndrome

Posted Date: November 19th, 2021

DOI: https://doi.org/10.21203/rs.3.rs-1032227/v1

License: (1) This work is licensed under a Creative Commons Attribution 4.0 International License. Read Full License 


\section{Abstract}

Background: The Fontan operation is the only treatment option to change the anatomy of the heart and help improve patients' hemodynamics. After successful operation, patients typically recover the ability to engage in general physical activity. The mortality of patients diagnosed with acute respiratory distress syndrome (ARDS) ranges from 17.3 to $41.4 \%$ among critically ill patients with H1N1 infection. As a better ventilatory strategy, extracorporeal membrane oxygenation (ECMO) provides gas exchange via an extracorporeal circuit, and is increasingly being used to improve respiratory and circulatory function. As is known to all, after the modified Fontan operation, circulation was different compared with patients who were not subjected to the procedure. But very few articles describe the special circulation about the case who was post-operative of the modified Fontan operation especially when it received the treatment of E$\mathrm{CMO}$. This study aims to describe a successful case using E-CMO in curing the influenza A infection in a young man, who was diagnosed with Tausing-Bing syndrome and underwent Fontan operation thirteen years ago. We want to explore the special cardiac structure and circulatory characteristics in this case.

Methods: To report a successful case using extracorporeal membrane oxygenation in curing the influenza A infection in a young man, who was diagnosed with Tausing-Bing syndrome and underwent Fontan operation thirteen years ago. In this article, we describe a 23-year-old man, with a history of modified Fontan operation for the Tausing-Bing syndrome, admitted to ICU with severe acute respiratory distress syndrome as a result of influenza $A$ infection. The man was initially treated by $\mathrm{V}-\mathrm{V}$ ECMO, five days later was switched to V-V-A E-CMO.

Results: As circulation and respiratory function gradually improved, the VV-A ECMO equipment was removed on May 1, 2018. The patient was successfully withdrawn from artificial ventilation on May 28, 2018, then discharged from hospital on May 30, 2018.

Conclusion: After the modified Fontan operation, circulation was different compared with patients who were not subjected to the procedure. There were certainly many differences between the two sides when they received the treatment of E-CMO. As the special cardiac structure and circulatory characteristics, an individualized liquid management strategy was necessary and it might be better for them to choose an active cycle support earlier.

\section{Introduction}

As we all known, the Fontan operation was the only treatment option to change the anatomy of the heart and help improve patients' hemodynamics [1]. The patient's circulation after the Fontan surgery was different than that of a normal patient. The mortality of patients diagnosed with ARDS ranges from 17.3 to $41.4 \%$ among critically ill patients with $\mathrm{H} 1 \mathrm{~N} 1$ infection [2-4], and many patients need the help of E$\mathrm{CMO}$. whereas, as the special circulation after the Fontan surgery, supporting Fontan patients on E-CMO carries high morbidity and mortality [5]. More detail about how we cure this young man in our hospital will be available in the following article. 


\section{Material And Methods}

\section{Ethical approval}

The patient gave his written permission for us to publish this manuscript.

\section{Case presentation[}

The case presented here refers to a 23-year-old college man. At birth, he was diagnosed with atrial septal defect, ventricular septal defect, pulmonary artery stenosis and right ventricular double outlet, also known as Tausing-Bing syndrome. He received the modified Fontan operation thirteen years ago when he was 10 years old. In this surgery, the pulmonary orifice was sutured, and the tricuspid valve was sewn closed, then the left auricle was connected with the pulmonary artery to ensure stable cardiopulmonary circulation during the operation. He recovered well and was able to perform general physical activity easily by himself after the operation.

Three years ago, the regular visit of echocardiography diagnosed a double outlet in the right ventricle, post Tausing-Bing syndrome operation. Moreover, it was also observed that he showed right atrial enlargement and aortic valve regurgitation. The ejection fraction of the young man was $50 \%$.

The young college student was admitted to the General ICU of Beijing Ditan Hospital affiliated Capital Medical University mainly due to fever for five days, with $39.1^{\circ} \mathrm{C}$ as highest temperature, without cough, sputum, abdominal pain, diarrhea, chest pain or other clinical symptoms. Then he received treatment at a local health clinic, where he was prescribed with cephalosporin antibiotics. Four days later, the patient saw a doctor at Beijing Huai Rou district hospital. The chest CT scan showed large consolidation of the lower lobe of the right lung and superior lobe of the left lung. The arterial blood gas analysis indicated: $\mathrm{pH} 7.476, \mathrm{PCO}_{2} 22 \mathrm{mmHg}, \mathrm{PO}_{2} 54.1 \mathrm{mmHg}, \mathrm{HCO}_{3}{ }^{-} 20.4 \mathrm{mmol} / \mathrm{L}$. The fraction of inspiration $\mathrm{O}_{2}$ the moment arterial blood specimens were taken was $21 \%$. Meanwhile, the antigen of influenza A was positive. Then he was transferred to the General ICU of Beijing Ditan Hospital affiliated Capital Medical University for further treatment on April 5, 2018.

The chest X-ray of the patient on admission was shown in Fig.1.

Laboratory tests the moment the patient was admitted to ICU were as follows: WBC $11.89 \times 10^{9} / \mathrm{L}$ (reference range, 4-10×10\% $/ \mathrm{L}$ ), NE\% 84.94\% (reference range, 50-70\%), HGB $173.10 \mathrm{~g} / \mathrm{L}$ (reference range, 110-150 g/L), HCT $48.70 \%$ (reference range, 35-45\%), PLT 178.00×10\% $/ \mathrm{L}$ (reference range, 100 $300 \times 10^{9} / \mathrm{L}$ ), Na $128.5 \mathrm{mmol} / \mathrm{L}$ (reference range, $137-147 \mathrm{mmol} / \mathrm{L}$ ), CREA $279.6 \mu \mathrm{mol} / \mathrm{L}$ (reference range, $41-73 \mu \mathrm{mol} / \mathrm{L}$ ), PCT $4.51 \mathrm{ng} / \mathrm{mL}$ (reference range, $\varangle 0.05 \mathrm{ng} / \mathrm{mL}$ ), CRP $212.9 \mathrm{mg} / \mathrm{L}$ (reference range, $0-5$ $\mathrm{ng} / \mathrm{ml}$ ), ALT 48.6 U/L (reference range,7-40 U/L), AST 100.4 U/L (reference range,13-35 U/L), TBIL 26.2 $\mu \mathrm{mol} / \mathrm{L}$ (reference range, 0-18.8 $\mu \mathrm{mol} / \mathrm{L}$ ), DBIL $21.4 \mu \mathrm{mol} / \mathrm{L}$ (reference range, 0-6.8 $\mu \mathrm{mol} / \mathrm{L}$ ). 
The patient was mainly diagnosed with type A influenza. Other diagnoses were pulmonary infection, severe respiratory failure, acute kidney injury, acute hepatic injury, electrolyte disturbance, atrial fibrillation. The moment the patient was admitted into ICU, APACHE II and SOFA score were respectively 22 and 10. A Venturi mask was used for supporting respiratory function, the oxygen flow volume was 15 $\mathrm{L} / \mathrm{min}$. The saturation of pulse oxygen of the patient was $80 \%$. Meanwhile, he had difficulty in breathing and breathed forty breaths per minute. The arterial blood gas analysis before mechanical ventilation indicated: $\mathrm{pH} 7.45, \mathrm{PCO}_{2} 30 \mathrm{mmHg}, \mathrm{PO}_{2} 48.2 \mathrm{mmHg}$. As for the severe ARDS, the young patient was intubated on April 5, 2018. The ventilator mode was IPPV. Other parameters were as follows: $\mathrm{FiO}_{2}=100 \%, \mathrm{VT}=560 \mathrm{ml}, \mathrm{f}=20$ times $/ \mathrm{min} \triangle \mathrm{PEEP}=10 \mathrm{cmH}_{2} \mathrm{O}, \mathrm{Ppeak}=23 \mathrm{cmH}_{2} \mathrm{O}$.

Moxifloxacin hydrochloride and Paramivir were used to combat infection once the patient was first admitted in ICU. Anti-infective drugs were switched to Cefoperazone-Sulbactam sodium and Vancomycin hydrochloride on April 9, 2018. To control a fungal infection, Voriconazole was used on April 9, 2018.

As the special heart structure post-operative of the modified Fontan operation, the central venous pressure (CVP) of the young man was $40 \mathrm{mmHg}$ on admission. As a result of septic shock, noradrenaline was used to raise blood pressure. As severe AKI, hyperkalemia and metabolic acidosis, continuous renal replacement therapy was initiated the moment he was admitted in ICU.

Even the protective lung ventilation strategy and ventilation in prone position were properly conducted after mechanical ventilation, his respiratory failure was persistent and did not significantly improved. The arterial blood gas analysis indicated as follows: $\mathrm{pH} 7.193, \mathrm{PCO}_{2} 48 \mathrm{mmHg}, \mathrm{PO}_{2} 52 \mathrm{mmHg}, \mathrm{BE}-10 \mathrm{mmol} / \mathrm{L}$, lac $1.34 \mathrm{mmol} / \mathrm{L}$. Veno-venous extracorporeal membrane oxygenation (V-V ECMO) was applied to correct the respiratory failure on April 6, 2018. The two vein indwelling catheters were established, respectively, in the left femoral and right internal jugular veins. The initial parameters of V-V ECMO were as follows: rotate speed=3100 turn $/ \mathrm{min}$; blood flow volume $=4.3 \mathrm{~L} / \mathrm{min}$; oxygen flow volume $=4.5 \mathrm{~L} / \mathrm{min} ; \mathrm{FiO}_{2}=100 \%$.

The chest X-ray of the patient First day accepted the V-V ECMO therapy was shown in Fig.2.

Enhanced chest CT scans were performed on April 9, 2018 as Fig.3 and Fig.4a shown. The report concluded that the heart showed post-operative changes, bilateral pneumonia changes. A small amount of bilateral pleural effusion was also detected. The direction of blood flow was as shown in Fig.4b.

As an attempt to ameliorate severe heart failure and cardiogenic shock, the V-V ECMO procedure was replaced by Veno-venous-artery extracorporeal membrane oxygenation (V-V-A ECMO) on April 11, 2018. The patient's right femoral artery was punctured and intubated as the infusion tube, and combined deep venous catheters of left femoral vein and right internal jugular vein were used as the drainage tube. The initial parameters of VV-A ECMO were as follows: rotate speed $=3800 \mathrm{turn} / \mathrm{min}$; blood flow volume $=4$ $\mathrm{L} / \mathrm{min}$; oxygen flow volume $=4 \mathrm{~L} / \mathrm{min} ; \mathrm{FiO}_{2}=100 \%$.

The chest X-ray of the patient second day and ninth day accepted the VV-A ECMO therapy were respectively shown in Fig.5 and Fig.6. 
We tried to use negative liquid equilibrium to improve the left heart failure at the early stage of VV-A ECMO. The negative fluid balance of the First and Second day were respectively 272 and $345 \mathrm{ml}$. As a result, the CVP of the young man decreased to $28 \mathrm{mmHg}$ and circulation of him tended to deterioration. In order to maintain circulation, the dose of noradrenaline had to adjust from 0.7 to $1.4 \mathrm{ug} / \mathrm{kg} / \mathrm{min}$. Then we tried to change the liquid management strategy. The cumulative positive balance is $10,000 \mathrm{ml}$ in the following seven days. The CVP of him gradually increased to $35 \mathrm{mmHg}$ and the dose of noradrenaline was gradually turned down until stopped on April 20, 2018.

The oxygenator and circulation line of ECMO were replaced as the equipment had achieved its design life on April 23, 2018.

As ventilator weaning was difficult in short period for the patient, tracheotomy was operated on April 27, 2018.

As circulation and respiratory function gradually improved, VV-A ECMO equipment was removed on May 1, 2018. The chest X-ray before the patient finished the VV-A ECMO therapy was shown in Fig.7.

The chest X-ray and CT scan of the lung imaging on May 24,2018 were shown in Fig.8 and Fig.9.

\section{Results}

The patient was successfully withdrawn from artificial ventilation on May 28,2018 , then discharged from hospital on May 30, 2018.

\section{Follow-up}

We followed him up at his home on October 25,2021, he can take care of himself in daily life and Engage in light manual labor.

\section{Discussion}

As research reported in 2005, double outlet right ventricle (DORV) occurs in 0.09 cases per 1000 live births. As a rare congenital heart disease, the Tausing-Bing anomaly (TBA) is the third most common type of DORV [6]. So far, the Fontan operation was the only treatment option to change the anatomy of the heart and help improve patients' hemodynamics [1]. After successful operation, patients typically recover the ability to engage in general physical activity.

H1N1 influenza has a higher case fatality among younger patients and the potential for fulminant acute respiratory distress syndrome (ARDS) [7]. The mortality of patients diagnosed with ARDS ranges from 17.3 to $41.4 \%$ among critically ill patients with $\mathrm{H} 1 \mathrm{~N} 1$ infection [2-4]. As a better ventilatory strategy, as well as an alternative mode of respiratory support, extracorporeal membrane oxygenation (ECMO) provides gas exchange via an extracorporeal circuit, and is increasingly being used to improve respiratory and circulatory function [8]. ECMO is usually used to help patients getting through post-operative 
difficulties such as heart failure, hemodynamically unstable and refractory arrhythmias. As the morbidity and mortality associated with ECMO are relatively high, the survival of children with heart disease that need ECMO support is only 33-60\% [9].

By analyzing the medical history and imaging manifestations, we concluded the direction of blood flow in this case was as shown in Fig.4b: Right Atrium $\rightarrow$ Pulmonary Artery $\rightarrow$ Pulmonary Vein $\rightarrow$ Left Atrium $\rightarrow$ Left Ventricle $\rightarrow$ Right Ventricle $\rightarrow$ Aorta $\rightarrow$ Right Atrium.

By analyzing data from the Extracorporeal Life Support Organization, we found that only $35 \%$ of cardiac failure patients subjected to Fontan operation survived to hospital discharge [10].

By analyzing the medical history and imaging results of the patient, there were mainly three factors causing the severe respiratory failure. Firstly, as the special physiological structure after the operation of Fontan, a single ventricle was more vulnerable to suffer severe left heart failure compared with a normal heart. Furthermore, pulmonary edema caused by the acute left ventricular failure was one of the reasons for respiratory failure. Secondly, the pulmonary infection caused by H1N1 influenza affected his respiratory function. Thus, severe ARDS might be the second cause of severe respiratory failure. Thirdly, pulmonary arterial hypertension might aggravate systemic circulation congestion on one side, which might lead to left ventricular preload insufficiency on the other side.

The patient's circulation after the Fontan surgery was different than that of a normal patient. Therefore, supporting Fontan patients on ECMO carries high morbidity and mortality [5]. After the Fontan operation, pulmonary and systemic circulation are mainly sustained by the single ventricle. A study found that patients for whom the Fontan operation was not successful usually suffered anatomic obstruction to flow, pulmonary vascular remodeling, atrioventricular valve dysfunction, univentricular diastolic dysfunction and chronic underfilling, and/or univentricular systolic dysfunction [11].

There are three stages of failure in a Fontan patient, each of which is associated with certain underlying etiologies [12]. Early Fontan failure is often marked by anatomic obstruction. Most patients usually have early acute onset of failure, prior to end organ injury [13]. Patients with middle and late phase Fontan failure usually exhibit signs of end organ damage. Late phase failure patients present protein losing enteropathy, plastic bronchitis, cirrhosis, or renal failure in the process of medical treatment [14]. In this case, after the Fontan operation, the right atrium of the patient was directly linked with the pulmonary artery. The CVP of the patient admitted in ICU was $40 \mathrm{mmHg}$, therefore he was diagnosed with pulmonary hypertension. As his circulation depended on the single ventricle, severe sepsis accelerated the process of heart failure. At the beginning of treatment, it was hard to improve the systemic and pulmonary circulation congestion.

Relevant research noted that about $30 \%$ of Fontan patients suffered from heart failure in 20 years [15, 16]. Patients with neurologic complications, surgical bleeding, and renal failure were inclined to have a higher mortality during the course of ECMO, indicating that ECMO complications may limit survival outcomes for these patients [10]. 
The patient initially received V-V ECMO treatment for severe respiratory failure on April 6, 2018. Even though the man's respiratory function significantly improved with the help of V-V ECMO, shock persisted and did not effectively relieve. By analyzing his heart anatomical structure of pathophysiological characteristics, we concluded that severe left heart failure might explain the refractory shock.

Then, in response to severe heart failure and cardiogenic shock, the V-V ECMO was converted to VV-A ECMO. The shock was significantly improved with the help of VV-A ECMO. Vasoactive drugs were disused in one day after the mode of the machine was switched.

We tried to use negative liquid equilibrium to improve the left heart failure at the early stages of VV-A ECMO, but failed. The negative liquid equilibrium was smoothly conducted three days after the mode of ECMO was changed. As pulmonary pressure of the case was high, the right ventricular ejection depended on pressure differences and needed a higher volume. With the improvement of cardiac function and oxygen, heart and respiratory failures were effectively improved. Meanwhile pulmonary arterial hypertension declined to some extent, making negative liquid equilibrium a feasible option. In the case, the proper CVP might be $35 \mathrm{mmHg}$. We had to search a suitable liquid state to balance both respiratory and circulatory systems. Therefore, an individualized liquid management strategy was necessary.

With the help of VV-A ECMO, heart failure and shock were gradually improved. After about 20 days of circulation support, the patient successfully got the rid of the VV-A ECMO equipment. As the special cardiac structure and circulatory characteristics, it might be better for him to choose an active cycle support earlier. Other modes such as V-A-V ECMO might be another choice especially for those who had a risk of differential hypoxia, which cardiac recovery preceded lung recovery [17]. For this case, V-A-V ECMO would provide Right Atrium oxygen-rich blood and improve coronary oxygen supply, which might be better for heart recovery.

Different types of antibiotics were used throughout the course of the disease. The structural abnormality of the heart and congestive heart failure increased pulmonary edema and aggravated pulmonary infection. Meanwhile, longer duration of ECMO increased the risk of bloodstream infection.

Although the outcome in our research was favorable, it is important to note that the case in my research took a longer ECMO course to achieve lung recovery[18]. Most previous studies had demonstrated the use of ECMO in patients with Fontan for cardiac support, but this case illustrated its value as a bridge to lung recovery in acute respiratory failure due to $\mathrm{pH} 1 \mathrm{~N} 1$ infection.

\section{Conclusions}

The circulation after the modified Fontan operation were different compared with those who did not suffer the operation. There were certainly many differences between the two sides when they received the treatment of ECMO. As the special cardiac structure and circulatory characteristics, it might be better for them to choose an active cycle support earlier. 


\section{Declarations}

-Ethical Approval and Consent to participate

The procedure we performed was approved by the ethics committee of our hospital. The patient gave us her written informed consent to undergo the procedure and to have her case published.

-Consent for publication

Written informed consent was obtained from the patient for publication of this manuscript and any accompanying images. A copy of the written consent is available for review by the Editor-in-Chief of this journal.

- Availability of supporting data

The data generated and analyzed during the current study are available from the corresponding authors on reasonable request.

- Competing interests

The authors declare that they have no competing interests

- Funding

This work was supported, in part, by funding from the Capital Foundation of Medical Development (20181-2171) and the Seedling Plan from the Beijing Ditan Hospital, Capital Medical University QDTYM201802Х. The design of the study and collection of data in this research were funded by the program.

-Authors' contributions

JYL and XTH designed the research study and provided research ideas. YCC, HFX, SCL, YFL, YS, LP, PX, $\mathrm{MZ}$, JJH, NNY read the literature and collected medical records. HBG and JBT were major contributors in writing the manuscript. All authors read and approved the final manuscript.

-Acknowledgements

Not applicable.

\section{References}

1. Peer SM, Deatrick KB, Johnson TJ, Haft JW, Pagani FD, Ohye RG, Bove EL, Rojas-Peña A, Si MS: Mechanical Circulatory Support for the Failing Fontan: Conversion to Assisted Single Ventricle Circulation-Preliminary Observations. World Journal for Pediatric \& Congenital Heart Surgery 2018, 9(1):31. 
2. T?Pfer L, Menk M, Weber-Carstens S, Spies C, Wernecke K-D, Uhrig A, Lojewski C, J? rres A, Deja M: Influenza A (H1N1) vs non-H1N1 ARDS: Analysis of clinical course. Journal of Critical Care, 29(3):340346.

3. Kumar, Anand: Critically III Patients With 2009 Influenza A(H1N1) Infection in Canada. Jama, 302(17):1872.

4. Kumar A, Zarychanski R, Pinto R, Cook DJ, Fowler RA: Critically III Patients With 2009 Influenza A(H1N1) Infection in Canada. Jama 2009, 302(17):1872-1879.

5. Rood KL, Teele SA, Barrett CS, Salvin JW, Rycus PT, Fynnthompson F, Laussen PC, Thiagarajan RR: Extracorporeal membrane oxygenation support after the Fontan operation. Journal of Thoracic \& Cardiovascular Surgery 2011, 142(3):504-510.

6. Walters HL, Mavroudis $\mathrm{C}$, ., Tchervenkov Cl, Jacobs JP, Lacour-Gayet F, ., Jacobs ML: Congenital Heart Surgery Nomenclature and Database Project: double outlet right ventricle. Annals of Thoracic Surgery 2000, 69(3):249-263.

7. Jaber S, ., Conseil M, ., Coisel Y, ., Jung B, ., Chanques G, . [ARDS and influenza A (H1N1): patients' characteristics and management in intensive care unit. A literature review]. Annales Franaises Danesthèsie Et De Rèanimation 2010, 29(2):117-125.

8. Brodie D: The Evolution of Extracorporeal Membrane Oxygenation for Adult Respiratory Failure. Annals of the American Thoracic Society 2018, 15(Supplement_1):S57.

9. Cooper DS, Jacobs JP, Moore L, Stock A, Gaynor JW, Chancy T, Parpard M, Griffin DA, Owens T, Checchia PA: Cardiac extracorporeal life support: state of the art in 2007. Cardiology in the Young 2007, 17 Suppl 2(S2):104.

10. Rood KL, Teele SA, Barrett CS, Salvin JW, Rycus PT, Fynn-Thompson F, Laussen PC, Thiagarajan RR: Extracorporeal membrane oxygenation support after the Fontan?operation. 142(3):504-510.

11. Anderson PA, Sleeper LA, Mahony L, Colan SD, Atz AM, Breitbart RE, Gersony WM, Gallagher D, Geva T, Margossian R: Contemporary outcomes after the Fontan procedure: a Pediatric Heart Network multicenter study. J Am Cell Cardio/ 2008, 52(2):85-98.

12. Bock MJ, Pahl E, Rusconi PG, Boyle GJ, Parent JJ, Twist CJ, Kirklin JK, Pruitt E, Bernstein D: Cancer recurrence and mortality after pediatric heart transplantation for anthracycline cardiomyopathy: A report from the Pediatric Heart Transplant Study (PHTS) group. Pediatric Transplantation 2017, 21(5):e12923.

13. Deal BJ, Costello JM, Webster G, Tsao S, Backer CL, Mavroudis C: Intermediate-Term Outcome of 140 Consecutive Fontan Conversions With Arrhythmia Operations. Annals of Thoracic Surgery 2016, 101(2):717-724. 
14. Woods RK, Ghanayem NS, Mitchell ME, Kindel S, Niebler RA: Mechanical Circulatory Support of the Fontan Patient \. Seminars in Thoracic \& Cardiovascular Surgery Pediatric Cardiac Surgery Annual2017, 20:20-27.

15. Yves DU, lyengar AJ, Galati JC, Victoria F, Weintraub RG, Wheaton GR, Andrew B, Justo RN, Grigg LE, Sholler GF: Redefining expectations of long-term survival after the Fontan procedure: twenty-five years of follow-up from the entire population of Australia and New Zealand. Heart Lung \& Circulation 2015, 24(1):e12-e12.

16. Oldenburger NJ, Mank A, Etnel J: Drug therapy in the prevention of failure of the Fontan circulation: a systematic review. Cardiology in the Young 2016, 26(5):842-850.

17. Vogel DJ, Josie M, Z. CA, Luigi C, Nicholas I, S. MCI, B. SP, Kathleen D, Nigel G, Nicholas B: Venoarterio-venous ECMO for septic cardiomyopathy: a single-centre experience. Perfusion, 33(1_suppl):57-64.

18. Gandhi NN, Hartman ME, Williford WL, Peters MA, Cheifetz IM, Turner DA: Successful use of extracorporeal membrane oxygenation for $\mathrm{pH} 1 \mathrm{~N} 1$-induced refractory hypoxemia in a child with hypoplastic left heart syndrome. Pediatr Crit Care Med, 12(6):e398-e401.

\section{Figures}

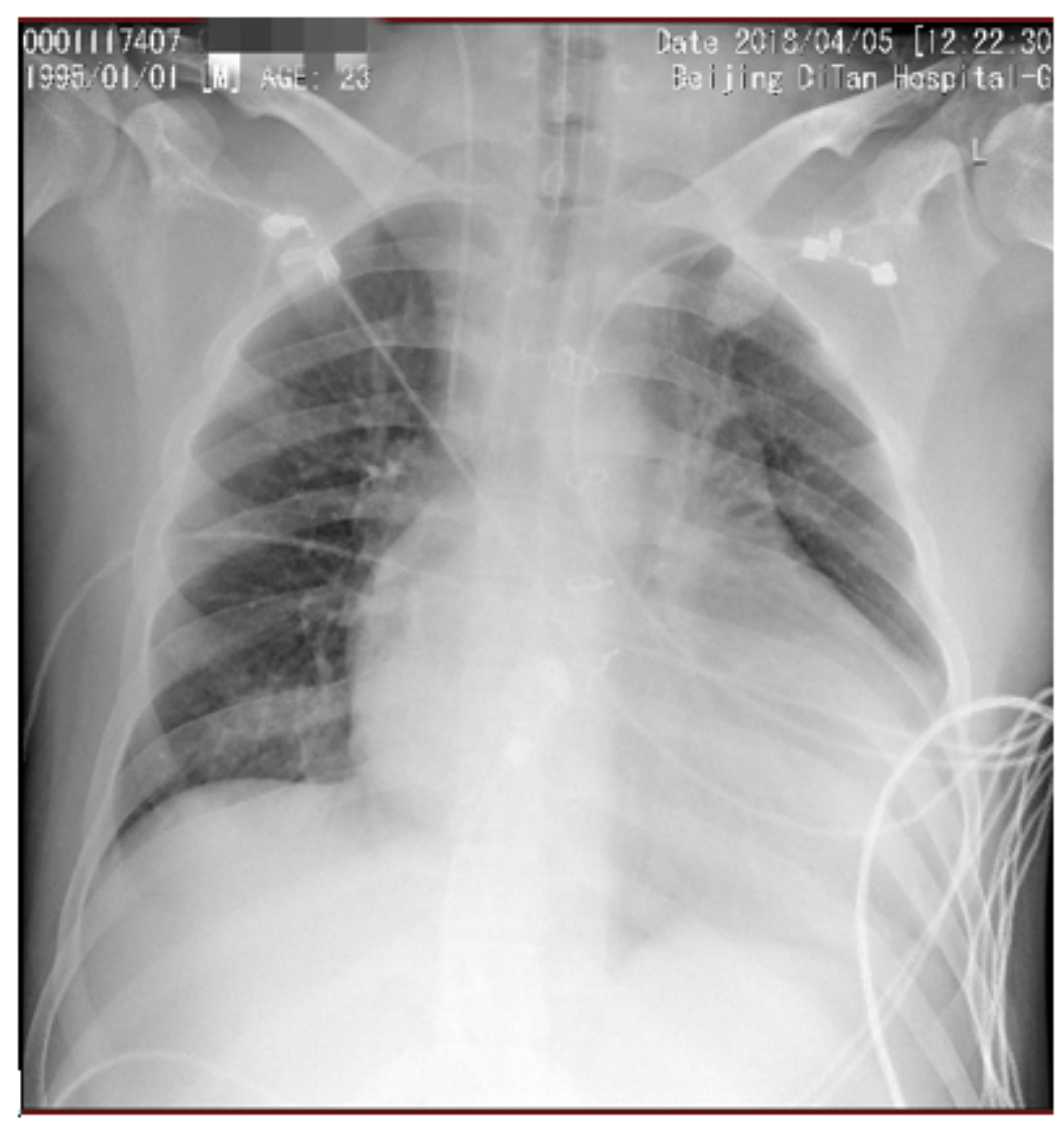

Figure 1 
Chest X-ray of the patient First day admitted to ICU

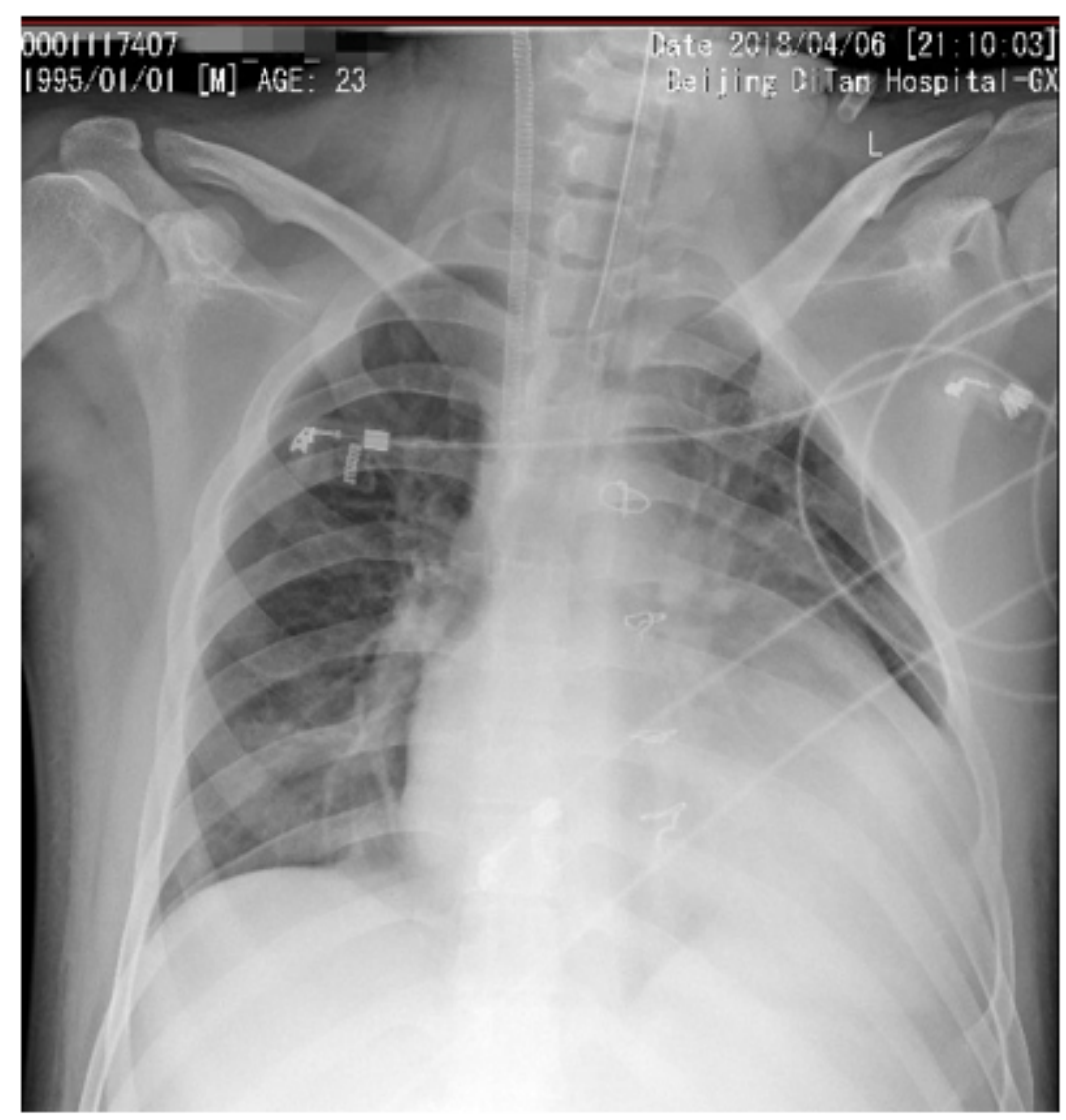

Figure 2

Chest X-ray of the patient First day accepted the V-V ECMO therapy

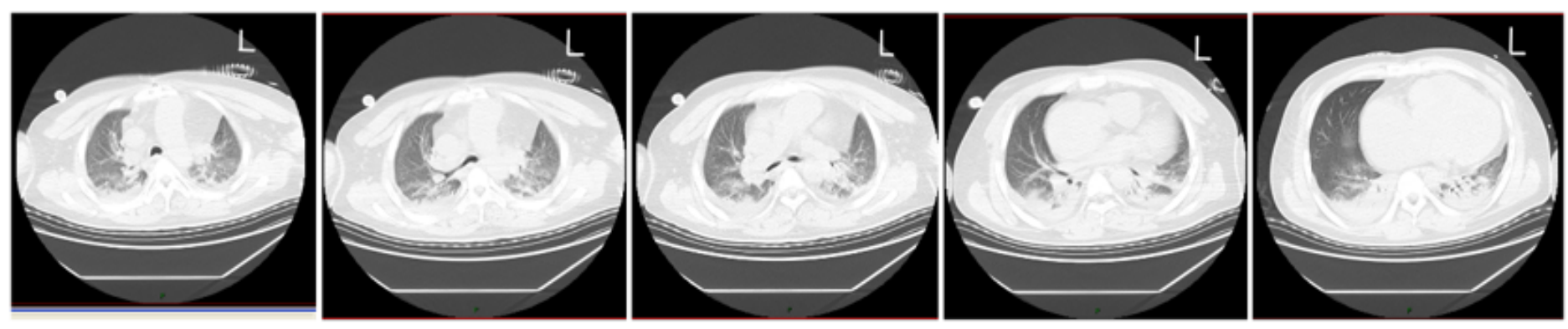

Figure 3

The CT scan of the lung imaging on April 9,2018 
(a)
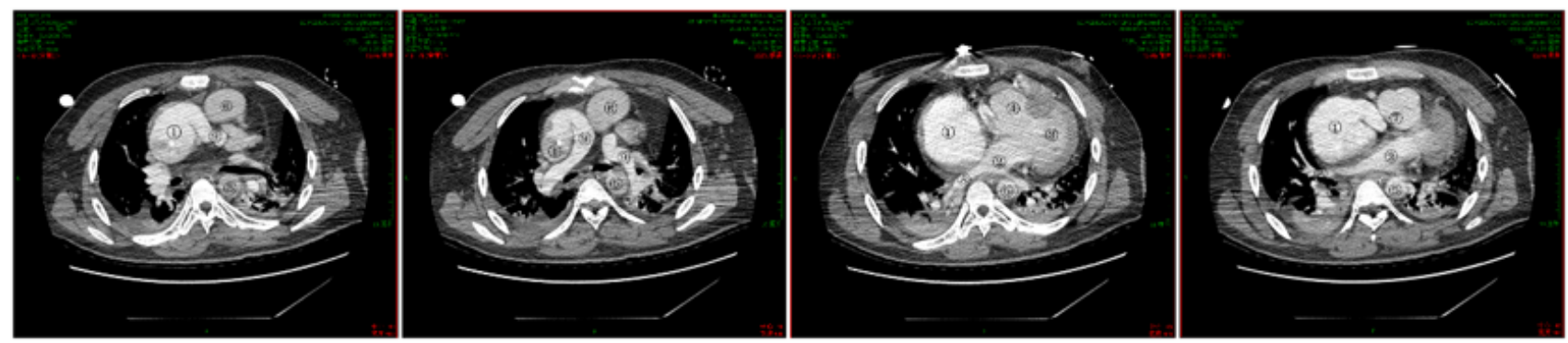

(b)

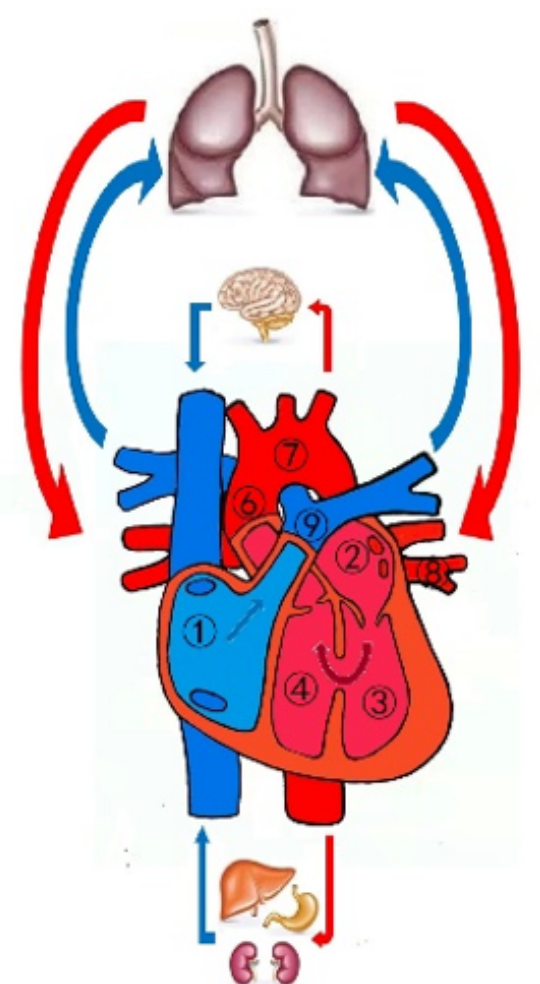

\section{Figure 4}

a The Chest enhanced CT imaging on April 9,2018 b The diagram of Fontan circulation $\otimes$ The right

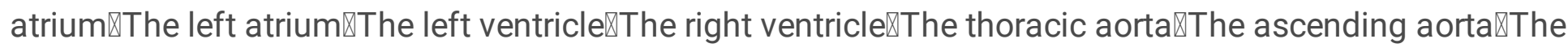
aortic arch $₫$ The pulmonary vein $\otimes T h e$ pulmonary artery 


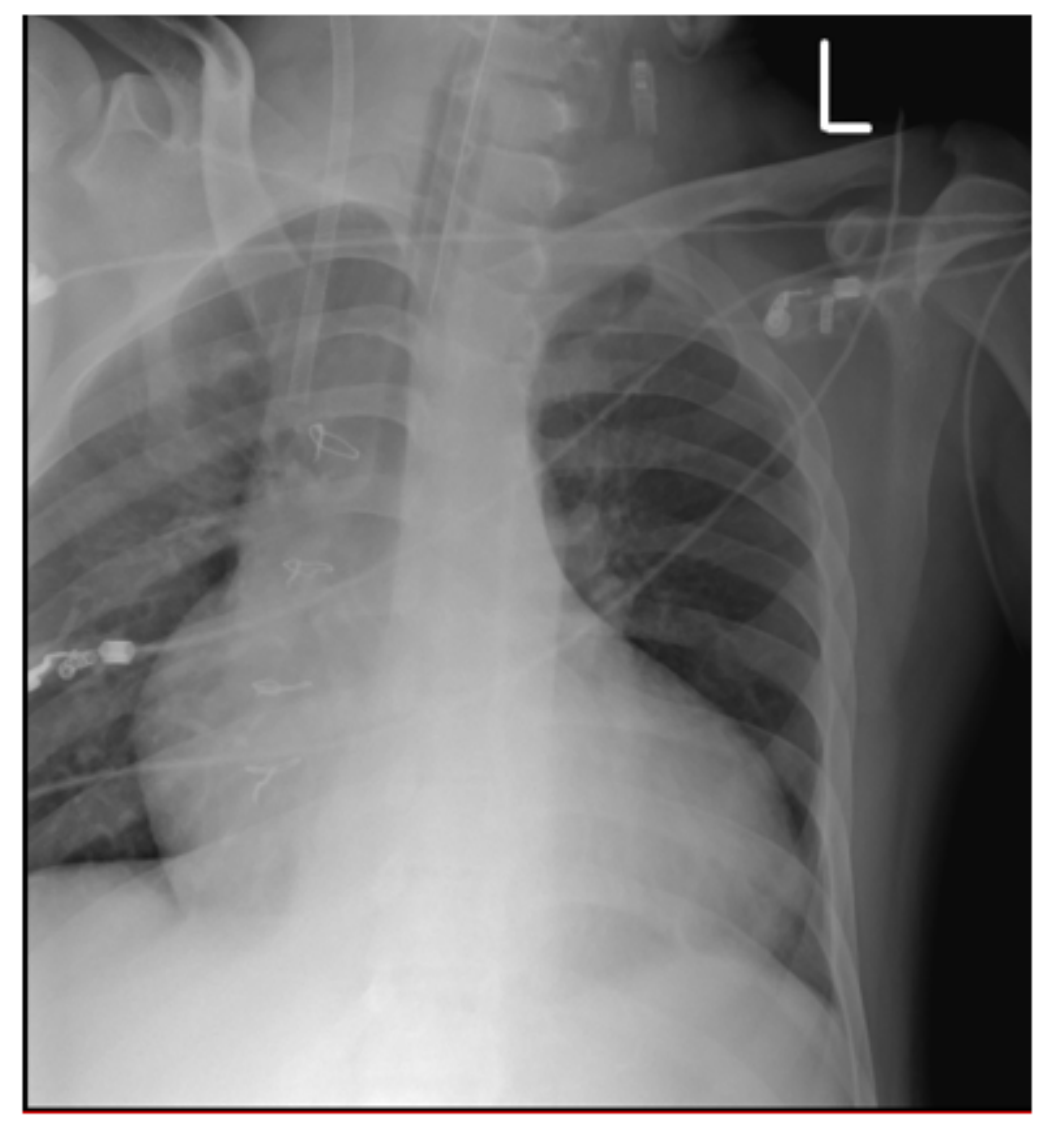

Figure 5

April 12,2018 Chest X-ray of the patient on the second day accepted the VV-A ECMO therapy 


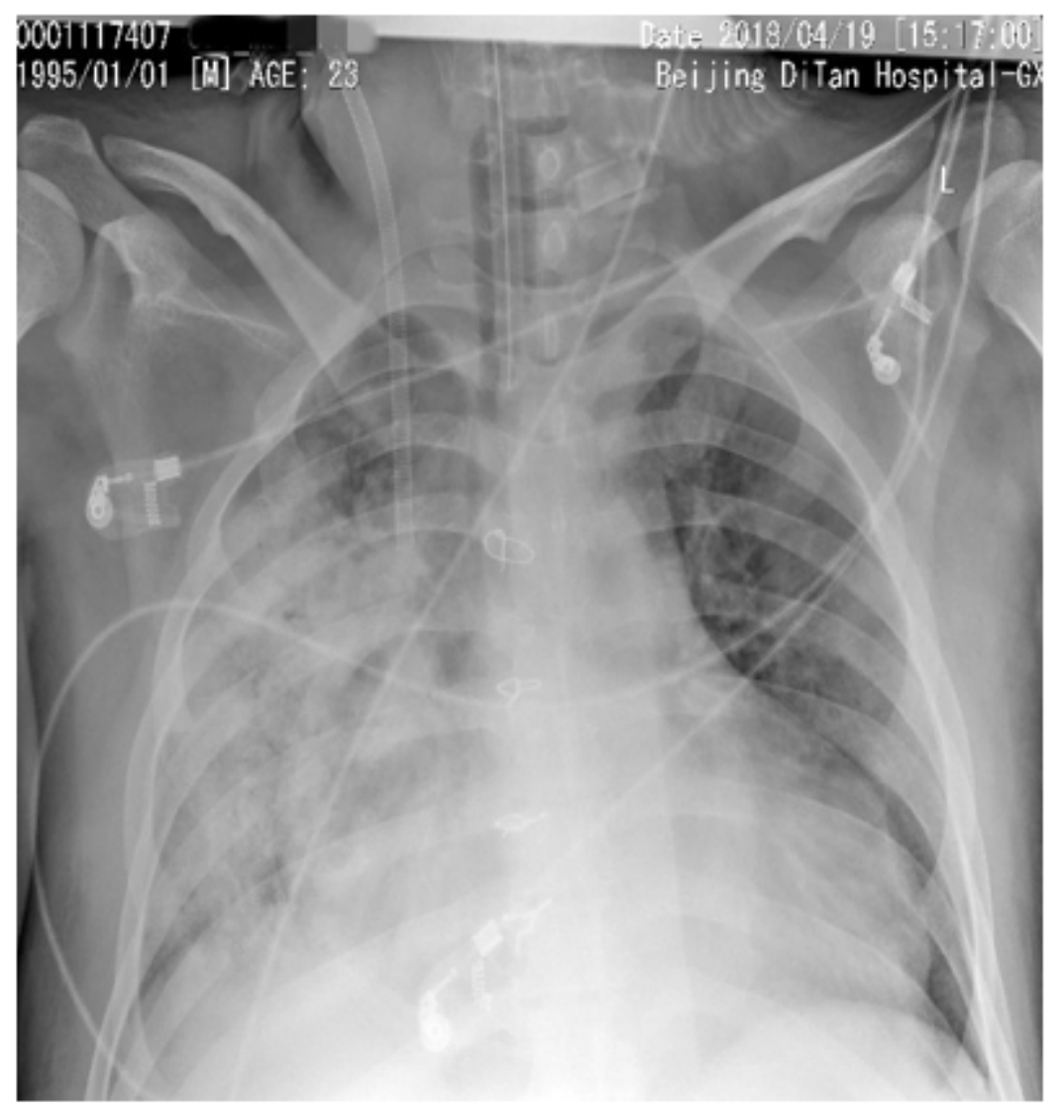

Figure 6

April 19,2018 Chest X-ray of the patient on the ninth day accepted the VV-A ECMO therapy 


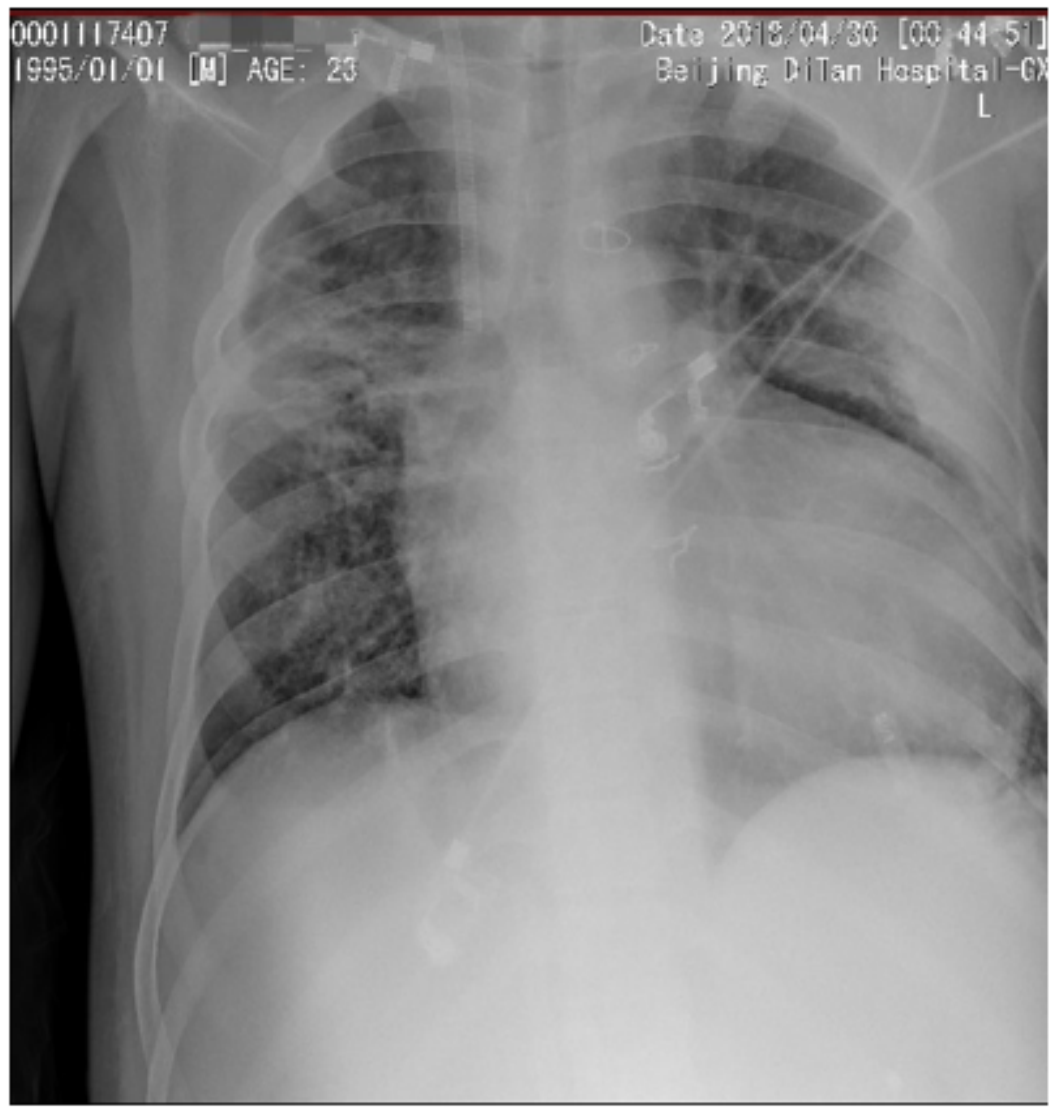

\section{Figure 7}

April 30,2018 Chest X-ray before the patient finish the VV-A ECMO therapy 


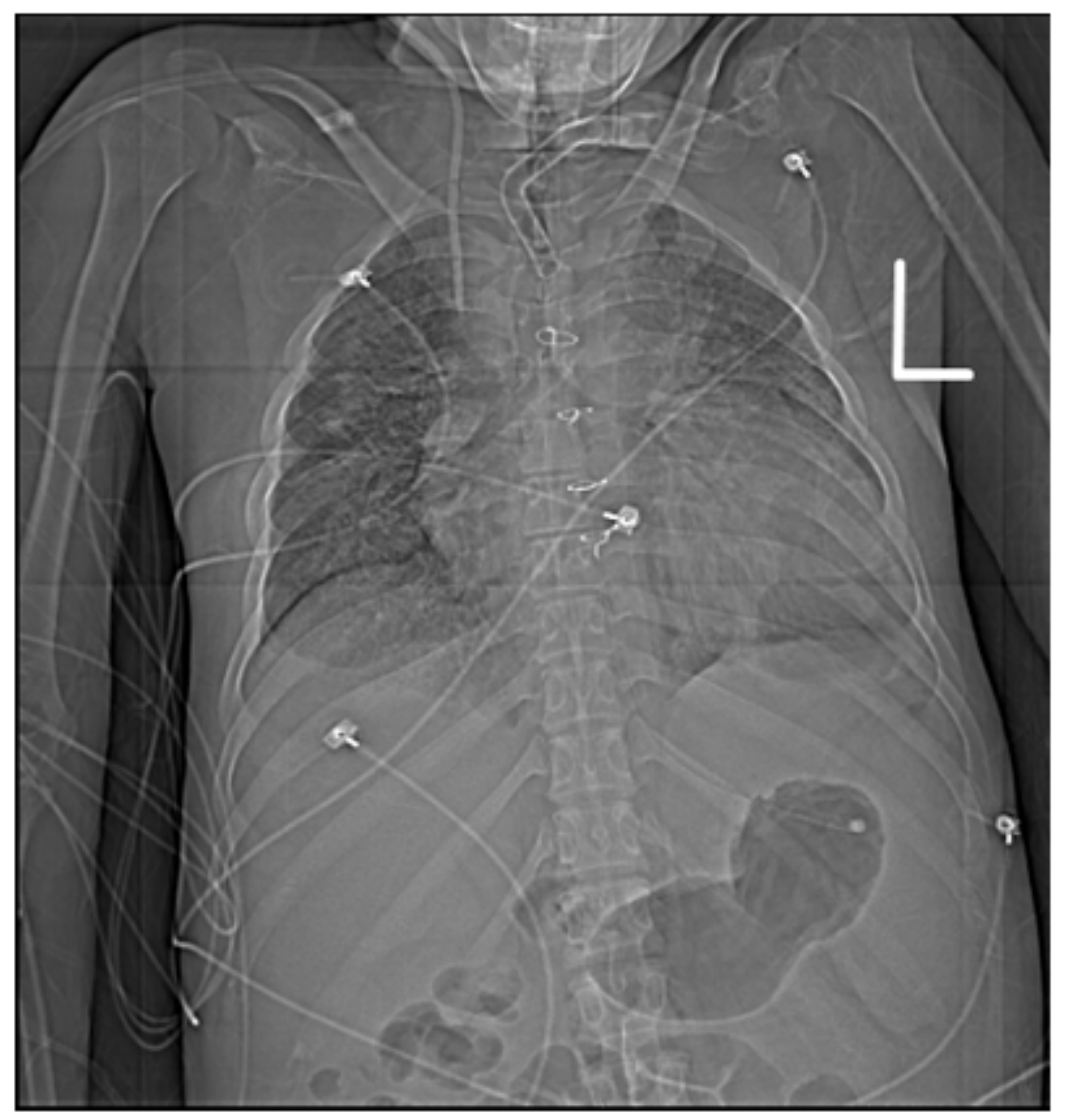

Figure 8

May 24,2018 Reexamine the chest X-ray

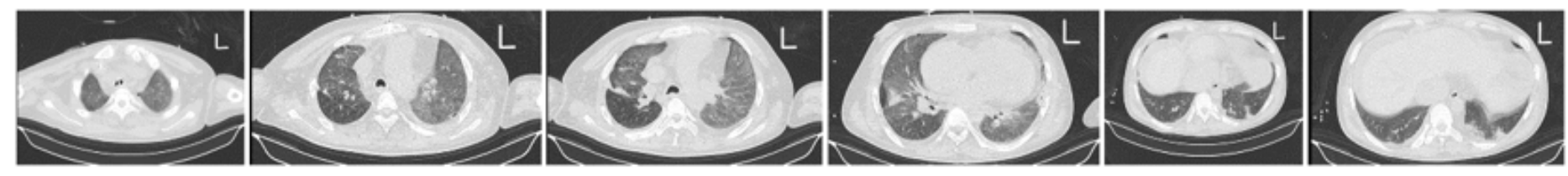

Figure 9

May 24,2018 CT scan of the lung imaging on May 24,2018 